\title{
Research of Improving Teaching Skills of College Teachers Based on TSW Mode
}

\author{
Chao WANG, Xiaomin ZHANG \\ School of Software, Nanyang Institute of Technology, Nanyang, 473004, Henan, China
}

\begin{abstract}
According to the present situation of quantity expansion, young tendency and insufficient training mechanism of college teachers, this paper first analyzes the necessity of enhancing teaching skills of college teachers, then discusses the main problem existed in current teacher training mechanism, finally put forward suggestions to solve these problems. It shows that the training mechanism based on TSW is feasible, which can improve teaching skills and the quality of talent training effectively.
\end{abstract}

KEYWORD: College teachers; Teaching skill upgrading; Training; TSW

The Eighteenth National Congress of the CPC put forward clearly to provide education that satisfies the needs of people, "promote connotation development of higher education", "improve the ranks of teachers, raise their professional ethics and competence and strengthen teachers' sense of honor and responsibility". At present, the competition in the era of knowledge economy is mainly talents and education and the latter one relies on the basic quality and ability of teachers. Yu \& Lu (2012) has said that the higher education of China is in a critical period of transformation that is from "quantity expansion" to "quality improvement and connotation development". It is critical to promote education and teaching reform, to realize connotation development of higher education, to cultivate high-quality, applied, compound and creative talents, and finally to improve teaching skills of college teachers effectively.

\section{THE NECESSITY OF TEACHING SKILLS IMPROVEMENT}

Teaching skills refer to teaching organization, teaching methods, teaching mode, teaching plan, teaching technology, teaching language, blackboard writing and so on. Qian \& Cui (2012) have presented us that the teaching skills contain basic teaching, decision-making, operation and research skills in teaching activities. Additionally, these skills also include dialogue, emotional experience, innovation, reflective practice, teaching communication, curriculum evaluation, ability to utilize information technology and so on. The level of teachers' teaching skills affects teaching and talent quality directly.
First, The Eighteenth National Congress of the CPC requires us to improve the ranks of teachers, "implement quality education fully, deepen comprehensive reform in the education field, improve education quality and cultivate students' sense of social responsibility, innovation and practice ability". The goal of college is to cultivate talents that are suitable for social development. As a result, the comprehensive quality of college teachers is the key factor and their teaching level, width and breadth of their knowledge can affect teaching effect greatly. Thus, it requires teachers to keep pace with the times, to master new knowledge and information quickly.

Second, it is helpful to realize oneself value. The contemporary college adopts a contract system instead of the traditional employment system. Teachers can adapt to college development and the new environment only by improving oneself ability to realize their teaching value. As the teaching leading roles, teachers can survive only by adapting to the requirement of college development so that they must have a creative spirit and self learning ability.

Third, it can promote the sustainable development of college. Teachers play a critical role in colleges and universities. Only the independent learning ability can promote teachers to adapt to new changing environment, which can also play a positive role in students' learning, life and job, and the college undertakings make healthy and orderly progress. In addition, the more independent learning ability teachers have, the more approval they can gain from students. Therefore it can improve social status of the college by making more and more people select this college and realize the sustainable college development possibility. 


\section{PROBLEMS EXISTED IN TEACHING SKILLS UPGRADING OF COLLEGE TEACHERS}

First, the number of college teachers has the feature of a faster growth rate in China at present. With the rapid expansion of college enrollment, the number of teachers in colleges and universities grows rapidly. In this group, the proportion of young teachers is high, take the school of software, Nanyang Institute of Technology (Nanyang, China) for example, the ages of new teachers is unduly 40 years old in the recent three years. Besides, new teachers' educational background is graduate, some of them graduate from the key universities of China such as 985, 211. Because the courses in colleges are extremely specialized, graduates in the same subject are usually selected as professional teachers. Mao (2011) has presented that although these teachers have profound professional knowledge and solid theoretical knowledge, most of them graduate from non normal majors and don't receive special occupation training. This will have direct effects: they have poor teaching skills and can't receive good teaching results.

Second, lesson plans are not complete. Lesson plans are text materials that are prepared for classroom teaching and practice teaching. It contains lesson plans, teaching plans, experimental guides, lecture notes and the teaching schedule. Standardized, scientific and complete lesson plans contain teaching purpose, teaching content, teaching method, time allocation, the emphasis and difficulties, the use of language, blackboard design, project cases, key points of review, classroom management, teaching postscript and so on. Owing to the lack of professional training of young teachers, there are many disadvantages such as non-standardized lesson plan formats, monotonous contents, simplistic and even no lesson plans.

Third, teaching methods are not novel. Lecture and rote learning are still the main teaching methods during the classroom teaching. Teachers lecture to all students according to teaching content and the teaching process has the characteristic of one-way communication. They are not familiar with heuristic and discussing teaching method, not to mention the use.

Fourth, teachers misuse the modern education technology. Due to computer medium used in classroom widely, young teachers master the making and using technology of multimedia courseware easily, but they can't combine it with the traditional blackboard teaching method. Therefore, the classroom is totally dependent on multimedia courseware. Teachers ignore the basic teaching skills training by using this kind of teaching method, and it lacks of communication between teachers and students. As a result, the teaching effect is much reduced.

\section{COUNTERMEASURES OF COLLEGE TEACHERS' TEACHING SKILLS DEVELOPMENT}

Teaching skills are one kind of ties that links teachers and students. It is only fluent and smooth which can produce good teaching effect. We can start from the following aspects based on the contemporary problems.

First, college teachers should enhance the consciousness, establish and improve teachers' teaching skills training system. The characteristics of college teachers' occupation force them to expand the depth and width of their knowledge continuously. There are many young and non normal college graduates as teachers in current colleges in China; they lack education theory and basic teaching skills. We should carry out training guides for this part of group, including the teacher occupation career planning, educational and teaching theory, and practice teaching skills. Meanwhile, we should assign a mentor with rich teaching and practice experiences for each new teacher. That mentor can help the new teacher improve teaching skills rapidly by demonstration teaching and teaching observation. Besides, we should carry out regular inspection and appraisal of teaching skills, such as three checks system, which has implemented at the beginning, middle and end of one semester. At the beginning, lesson plans and teaching notes are checked, at the middle, status and effect of classroom teaching are checked, at the end, teaching analysis and examination assessment are checked. It suggests that teaching skills competition is carried out regularly for young teachers and it can also promote their teaching skills by colleague's evaluation, supervisor's evaluation, expert's evaluation and student's evaluation. Yuan \& Yuan (2011) have said that colleges should encourage teachers to participate in teaching seminars in order to learn something and share advanced teaching idea and teaching skills.

Second, we should renew education ideas and teaching thoughts for the purpose of adapting to new demand for talent cultivating. Talent cultivation is core for the teaching reform in higher education; the final purpose of college teacher development and teaching skill improvement is to promote all-round development of students. Teachers in colleges should establish education ideas with the characteristic of "student-oriented" and all-round development of students, apply these ideas to teaching reform and practice, pay attention to the cultivation of students' knowledge and ability, develop their sense of independent study, and encourage them to develop their personalization. Only by doing this, the teaching level and the quality of talent training are improved.

Third, we should promote teachers' teaching skills based on TSW (Teaching Skill Workshop) mode, a strengthening centralized training mode. It can 
improve teaching skills of the participants by way of a workshop. The main characteristic is teachingpractice based, supplemented by teaching theory. It can let teachers learn to teach, and vice versa, meanwhile, it combines practice and theory together. The main features are as follows:

(1) Organize regular seminars. We should divide teachers into group, from three to five persons in each group. Each member of the group not only make teaching training for themselves, but also listen to other people's lessons seriously and give feedback depending on the requirements. This kind of organization can enable participants to get exercise and improvement in the environment of equality and mutual assistance, mutual learning, and collaborative work. Members of the group can learn from others' strong points and close the gap and improve the learning efficiency as well. We can focus on some teaching problems such as classroom design and teaching methods at seminar by using micro teaching and micro classroom teaching, find our deficiencies by discussion, draw lessons from other people's practices and suggestions by rethinking, analysis, reference and improvement. Advanced teaching methods and skills are helpful to promote all-round development of students, and the use of them will finally improve one's own teaching skills.

(2) Implement targeted training for teachers. TSW training mode has specific requirements for each teaching step during the teaching process. Detailed analysis and design should be made with "Bring(B)", "Objective(O)", "Prepare(P)", "Share(S)", "Check $(C)$ ", "Summary(S)" in each class. "B" clarifies the class value to the students and guides the students' learning motivation in an appropriate way; "O" tells learners what to do, what kind of learning environment is best for them, what learning level should they reach; "P" finds out whether students have associated knowledge and achieve the targeted goals, whether the environment and resources needed by classroom are fully prepared; "S" mainly includes learning time, teacher activities, student activities and teaching resources, learning time means time required by shared learning, teacher activities refer to what the teacher should do in order to promote students' learning, student activities are the practice of students, teaching resources are shared resources; "C" are used to determine whether students have achieved the expected goals by checks after class; Another " $S$ " for summary is used to evaluate this lesson after class to find out advantages and disadvantages for the next improvement. These six elements are the direct embodiment of teaching skills. Only careful design and each element completed can guarantee every class's success.
(3) Set up scientific and reasonable training cycle. We should set up a reasonable training cycle in order to make young teachers master basic teaching skills quickly and form their own teaching styles. Generally speaking, each participant in TSW should prepare three classes, write three teaching plans, organize three classroom teaching activities and give feedbacks to other participants as a student. The first training let the participant know how to organize a class, the second training let the participant familiar with the classroom organization methods, the third training helps them to form a good teaching habit and achieve the expected teaching effect. Moreover, teaching time for each participant is limited to ten minutes, these participants will not be dispersed too much effort to prepare for the course content, instead they can focus on teaching skills and styles, likewise for listeners, this period is not too long and it is easy to grasp the main points.

\section{SUMMARY}

Modern society has entered the era of lifelong learning. The development goal of this society is to create a "learning-oriented society". In this paper, how to improve college teachers' teaching skills is proposed, and one teaching method based on TSW mode is introduced. This applicable method is used to guide teachers for training, and can be implemented in daily teaching activities. College teachers as a lifelong learner should take discipline teaching as the basis, and promote sustainable development of one's own by lifelong learning. They, consequently, cultivate the new high-quality talents that can satisfy the society needs and improve their social service ability. In the later teaching work, we will continue to explore and study in order to seek more and more reasonable and effective methods to perfect teaching skill training mode of college teachers.

\section{REFERENCES}

[1] Mao Hongtao. 2011. Mechanisms to improve the education and teaching ability of teachers in colleges and universities. China Higher Education (23): 35-37.

[2] Qian Guoying, Cui Yanqun. 2012. Combining evaluation and training to establish the benign development mechanism of teachers. China University Teaching (2): 6668.

[3] Yu Changli, Lu Qingli. 2012. Analysis of the teaching ability of teachers to achieve the effective teaching. Education Exploration (8): 103-106.

[4] Yuan Zhizhong, Yuan Daixiu. 2011. Ways to improve college teachers' teaching ability. Forum on Contemporary Education (3): 65-67. 